\title{
Global changes in gene expression by the opportunistic pathogen Burkholderia cenocepacia in response to internalization by murine macrophages
}

\author{
Jennifer S Tolman ${ }^{1}$ and Miguel A Valvano $12^{*}$
}

\begin{abstract}
Background: Burkholderia cenocepacia is an opportunistic pathogen causing life-threatening infections in patients with cystic fibrosis. The bacterium survives within macrophages by interfering with endocytic trafficking and delaying the maturation of the $B$. cenocepacia-containing phagosome. We hypothesize that $B$. cenocepacia undergoes changes in gene expression after internalization by macrophages, inducing genes involved in intracellular survival and host adaptation.

Results: We examined gene expression by intracellular B. cenocepacia using selective capture of transcribed sequences (SCOTS) combined with microarray analysis. We identified 767 genes with significantly different levels of expression by intracellular bacteria, of which 330 showed increased expression and 437 showed decreased expression. Affected genes represented all aspects of cellular life including information storage and processing, cellular processes and signaling, and metabolism. In general, intracellular gene expression demonstrated a pattern of environmental sensing, bacterial response, and metabolic adaptation to the phagosomal environment. Deletion of various SCOTS-identified genes affected bacterial entry into macrophages and intracellular replication. We also show that intracellular B. cenocepacia is cytotoxic towards the macrophage host, and capable of spread to neighboring cells, a role dependent on SCOTS-identified genes. In particular, genes involved in bacterial motility, cobalamin biosynthesis, the type VI secretion system, and membrane modification contributed greatly to macrophage entry and subsequent intracellular behavior of $B$. cenocepacia.

Conclusions: $B$. cenocepacia enters macrophages, adapts to the phagosomal environment, replicates within a modified phagosome, and exhibits cytotoxicity towards the host cells. The analysis of the transcriptomic response of intracellular B. cenocepacia reveals that metabolic adaptation to a new niche plays a major role in the survival of B. cenocepacia in macrophages. This adaptive response does not require the expression of any specific virulenceassociated factor, which is consistent with the opportunistic nature of this microorganism. Further investigation into the remaining SCOTS-identified genes will provide a more complete picture of the adaptive response of B. cenocepacia to the host cell environment.
\end{abstract}

\section{Background}

Burkholderia cenocepacia is a member of the B. cepacia complex (Bcc), which comprises at least 17 closely related bacterial species $[1,2]$. Ubiquitous in nature, Bcc bacteria thrive in the rhizosphere, fresh and marine water, and in association with amoebae, fungi, insects, plants and

\footnotetext{
* Correspondence: mvalvano@uwo.ca

${ }^{1}$ Infectious Diseases Research Group, Department of Microbiology \& Immunology, University of Western Ontario, London, Ontario, N6A 5C1, Canada

Full list of author information is available at the end of the article
}

animals [3,4]. Members of the complex have biopesticidal and plant growth-promoting properties [5], and due to their metabolic diversity, also have the ability to degrade environmental pollutants [6]. The beneficial properties of Bcc bacteria, however, are offset by their opportunistic pathogenicity in immunocompromised individuals, especially in cystic fibrosis $(\mathrm{CF})$ patients $[7,8]$.

Bcc-infected CF patients suffer a rapid decline in lung function [9], and some develop "cepacia syndrome", a fatal condition characterized by rapid lung deterioration, acute, necrotizing pneumonia, and septicemia [8]. Resistance to

\section{Biomed Central}


almost all clinically relevant antibiotics [10] and patientto-patient transmission further complicate treatment and prevention [11-13]. Nearly all species of the Bcc have been identified in the sputum of CF patients, but B. cenocepacia and $B$. multivorans are the most prevalent $[14,15]$. Of these, B. cenocepacia is associated with epidemic spread and more severe infection $[15,16]$, and is thus the focus of this study.

Environmental strains of $B$. cenocepacia have been isolated from CF patients, indicating a single strain can occupy multiple niches $[12,17]$. This suggests an adaptive capacity of these bacteria to different and potentially stressful environments, which likely requires gene transcription. B. cenocepacia has a very large genome $(\sim 8$ $\mathrm{Mbp}$ ) arranged in three chromosomes and one plasmid [18]. The genome encodes many putative virulence factors, but none has been shown to be completely necessary for survival [for a recent review see reference [19]]. Therefore, little is known about the mechanisms by which $B$. cenocepacia causes disease. Bacterial survival within host cells, including epithelial cells [20] and macrophages [21-23], may potentially provide a reservoir for bacterial persistence [24]. Intracellular B. cenocepacia delay phagosomal maturation $[21,25]$ and assembly of the NADPH oxidase $[26,27]$, and alter the actin cytoskeleton [27-29]. Furthermore, intracellular B. cenocepacia can replicate within macrophages [30]. The bacteria-containing phagosome fuses with the lysosome and becomes acidified by $6 \mathrm{~h}$ post-infection [21], suggesting that $B$. cenocepacia may be able to replicate in an acidic environment.

To gain a full picture of bacterial adaption to the macrophage cell host we investigated the gene expression of intracellular bacteria upon internalization into macrophages. The study of gene expression by intracellular bacteria is challenging since bacterial mRNA, which has a short half-life, represents only a small fraction of total bacterial RNA, which itself is only a small fraction of the total RNA in infected host cells. Selective capture of transcribed sequences (SCOTS) is a technique developed to address these challenges and identify bacterial genes expressed during infection. Previous studies in other bacteria have shown that SCOTS enriches microbial transcripts without introducing a significant bias in gene expression data [31]. This technique has been used to identify genes expressed by several intracellular pathogens, including Mycobacterium tuberculosis [32], Salmonella enterica serovar Typhi [33,34], Escherichia coli O157:H7 [35], Legionella pneumophila [31], and Ehrlichia ruminantium [36].

In this study, we characterized gene expression by intracellular B. cenocepacia during an early post-infection stage in an attempt to identify gene products involved in bacterial adaptive responses to the phagosomal environment. We demonstrate that $B$. cenocepacia alters gene expression post-internalization, and that various upregulated genes are involved in bacterial entry, intracellular replication, and cytotoxicity towards the macrophage host.

\section{Results and discussion}

Low abundance transcripts identified by competitive enrichment

SCOTS was used to examine gene expression by intracellular B. cenocepacia in murine macrophages at $4 \mathrm{~h}$ post-infection. This interval was selected because at $4 \mathrm{~h}$ post-infection most intracellular bacteria reside in phagosomes that do not fuse with the lysosome [21,26,37]; infected macrophages also display observable alterations of the actin cytoskeleton caused by the bacterial Type VI secretion system (T6SS) [27,28], which is poorly expressed in LB medium [28]. Therefore, $4 \mathrm{~h}$ post-infection provides a good window to document early changes in bacterial gene expression in response to the intracellular environment. As a control, we used bacteria grown for $4 \mathrm{~h}$ in macrophage growth medium (DMEM-10\% FBS). To isolate and enrich bacterial transcripts, three rounds of SCOTS were performed on both intracellular and control bacterial cDNA samples. The resultant cDNA pools were subjected to competitive enrichment for transcripts specific to intra-macrophage bacteria. This was accomplished by pre-blocking the chromosome with both rDNA and control cDNA from non macrophage-exposed bacteria prior to capturing the cDNA from intracellular bacteria. The procedure facilitates capture of bacterial transcripts that are preferentially expressed within the phagosome. After three rounds of competitive enrichment, intracellular cDNA sequences were cloned into pUC19 and introduced into $E$. coli DH $5 \alpha$ by transformation. DNA inserts from colonies were individually amplified by PCR and screened by Southern blot for differential hybridization to digoxigenin-labeled cDNA libraries. Many of the recombinant plasmids obtained hybridized to labeled intracellular cDNA but not to non macrophage-exposed cDNA (Additional file 1, Figure S1). One hundred eighteen unique sequences, encoding 124 proteins, were mapped to the B. cenocepacia genome (Additional file 2, Table $\mathrm{S} 1$ ); of these sequences, four were secondary sequences within an already identified gene, two were within a duplicated region on chromosome one, and one was a transposase gene with nine identical copies distributed throughout the genome. Identified sequences were proportionally represented in each of the three chromosomes and the plasmid: 57 sequences mapped to chromosome one, 51 to chromosome two, 14 to chromosome three, and 2 to the plasmid. Identified genes were classified into functional categories based on clusters of orthologous genes (COG) designations (Figure 1). Almost half (46\%) of identified 


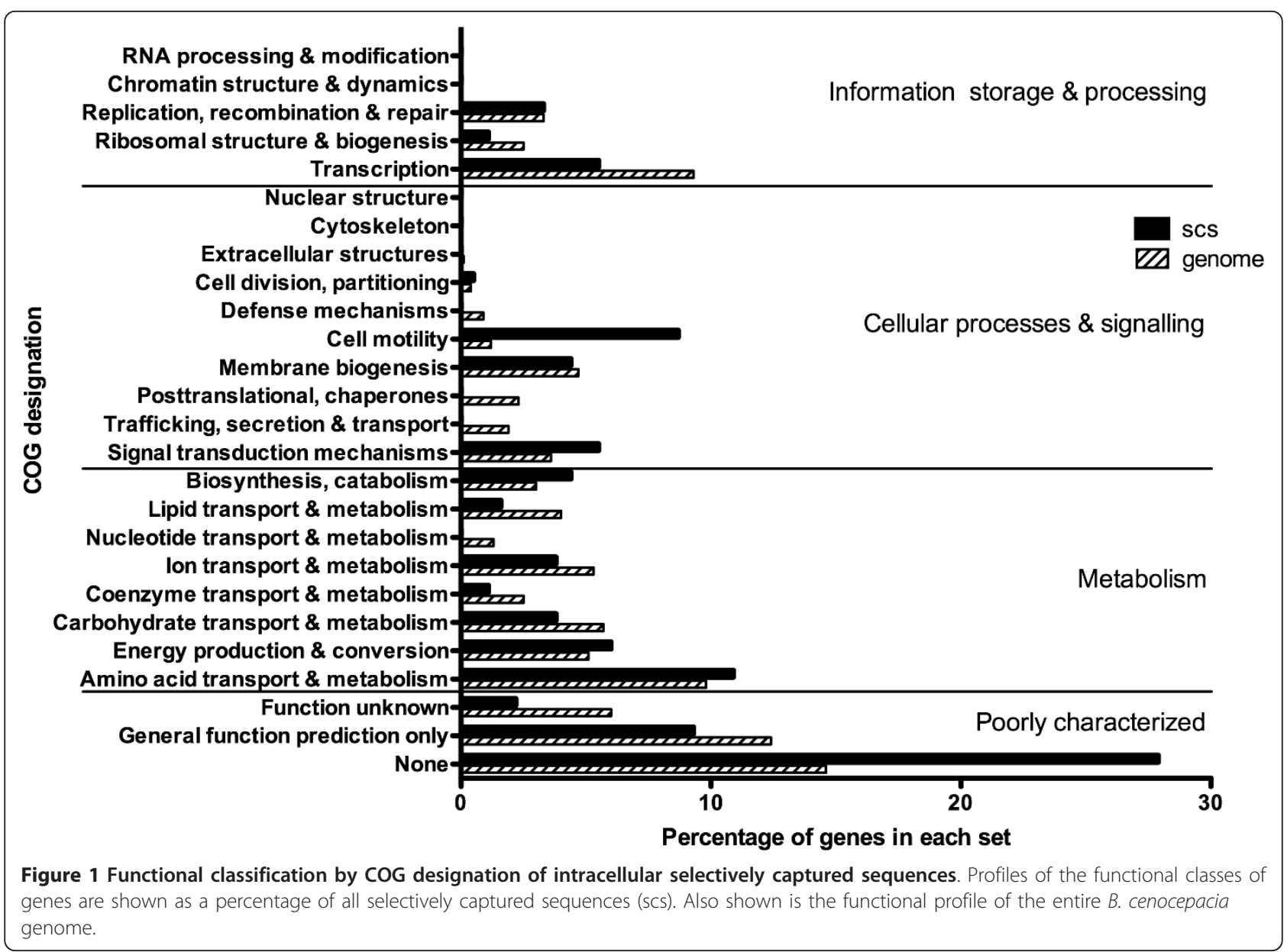

genes belonged to the category of poorly characterized genes, of which two-thirds had no COG classification. Of the remaining genes, half were involved in metabolism, one-third in cellular processes and signaling, and the remainder in information storage and processing. Several major COGs were not represented in the set, including genes encoding functions of nucleotide metabolism and transport, trafficking, secretion and transport, posttranslational modification and chaperones, and defense mechanisms. In contrast, genes classified as encoding cell motility functions were overrepresented relative to genome content. Competitive enrichment and downstream screening do not require specialized equipment, significant financial outlay, or additional knowledge of the genome, and are thus easily and rapidly applicable to any bacterium of interest. Applying competitive enrichment to SCOTSderived cDNA identified trends in the intracellular behavior of B. cenocepacia, as well as specific gene targets for further study. However, analysis of global changes in gene expression requires a high-throughput screening system.
Global intracellular gene expression identified by microarray analysis

To determine if the trends of intra-macrophage expressed genes are representative of the entire cDNA library, SCOTS-derived cDNA pools were applied to B. cenocepacia-specific microarrays. Each cDNA pool was hybridized against a reference sample of genomic DNA, allowing comparison between samples. Of the 118 sequences initially identified by competitive enrichment, 80 percent showed higher expression by intracellular bacteria than non-macrophage-exposed bacteria, validating the use of competitive enrichment as a preliminary investigation technique. Twenty percent of sequences identified by competitive enrichment showed significant intracellular upregulation ( $>2$-fold, $p<0.05$ ) of the gene itself or putative transcriptionally associated gene (s). In a global comparison of gene expression between intracellular and non-macrophage-exposed bacteria, 767 genes or intergenic sequences demonstrated significant changes in expression $(-2>\log 2>2, \mathrm{p}<0.05)$ (Additional file 3, Table S2), from which 330 and 437 showed 
increased and decreased expression, respectively. The gene distribution among the three chromosomes and the large plasmid of $B$. cenocepacia was relatively proportionate to the size of the genetic element (Figure 2), with the exception of the plasmid, where $20 \%$ of all plasmid-encoded genes showed decreased expression by intracellular bacteria.

To validate our results we first determined how many of the genes obtained by the SCOTS method were previously identified by signature-tagged mutagenesis (STM) as essential for in vivo survival. In the previous study we mapped 84 unique transposon insertions in genes that were associated with attenuation of bacterial survival in a rat agar bead model of chronic lung infection [38]. Four of the STM genes were identified directly by SCOTS using competitive enrichment, and another three SCOTS-identified genes were found in genes located within a putative transcriptional unit with an STM insertion (Additional file 4, Table S3). The microarray analysis identified an additional 26 of the 84 STM genes as being more highly expressed by intracellular bacteria than non-macrophage-exposed bacteria. These results were considered significant since bacterial survival in a rat agar bead model involves more that just intra-macrophage survival.

A more direct validation of the SCOTS gene set was performed by quantitative RT-PCR using a subset of genes. Because bacterial RNA accounts for a very small proportion of the total RNA isolated from infected cells, an internal control was necessary to allow comparison across samples. Sigma factor BCAM0918, or rpoD (also designated $\operatorname{sig} A$ [39] or $\operatorname{sig} E[39,40])$ was chosen due to stable expression across growth phases and conditions [41]. Despite reverse transcribing equal amounts of RNA for each sample, intracellular samples averaged 60-fold less rpoD transcripts than in non macrophage-exposed samples, demonstrating the scarcity of bacterial RNA relative to eukaryotic content in the intracellular sample. To account for this problem, expression of the gene of interest was first related to the internal control, and this ratio was compared between samples to give fold increase in expression in intracellular bacteria. The test genes included BCAM0314 (hypothetical protein), BCAM2141 (ABC transporter ATP-binding protein), BCAM0276 (putative universal stress protein), and BCAS0186 (putative acyl carrier protein phosphodiesterase), all of which show high expression in intracellular bacteria. BCAM1928 (putative transcription elongation factor) was chosen as an example of a gene with decreased expression in intracellular bacteria. qRT-PCR confirmed higher expression of BCAM0314, BCAM2141, BCAM0276, and BCAS0186 (Additional file 5, Figure S2); expression of negative control BCAM1928, though detectable in both samples, was far lower in intracellular bacteria than in non- macrophage-exposed bacteria, with a fold change ratio of $3.2 \times 10^{-3} \pm 2.8 \times 10^{-3}$. Based on the comparison of the SCOTS results with STM data and the results of qRTPCR, we concluded that the set of genes identified by microarray provides a good representation of the $B$. cenocepacia transcriptome in the phagosome at $4 \mathrm{~h}$ post infection.

Differentially regulated genes identified by microarray were classified into functional categories based on COG designations (Figure 3). Globally, our results indicate that internalization of $B$. cenocepacia by macrophages causes large changes in the expression of genes associated with signal transduction mechanisms and transcription, showing that B. cenocepacia senses the phagosomal environment and activates mechanisms necessary for survival in a new niche. Adaptive gene expression is a continual process, as transcription-associated genes remain among the most-affected at $4 \mathrm{~h}$ post-infection (Figure 4). Metabolic adaptation accounts for one-third of differentially regulated genes in intracellular bacteria. In particular, genes involved in carbohydrate transport and metabolism were prominently upregulated in intracellular bacteria, accounting for $6 \%$ of all differentially upregulated genes (Figure 3). In Leishmania, a protozoan parasite that delays phagosomal maturation and replicates in an acidified phagolysosome, the phagolysosome contains various carbon sources and essential nutrients, but lacks carbohydrates [42], which could explain the upregulation of carbohydrate metabolism pathways. We speculate that in similar fashion, the upregulation by intracellular B. cenocepacia of genes involved in carbohydrate metabolism is a consequence of the low carbohydrate content in the phagosomal lumen. This also agrees with the observation that some of the most highly expressed genes in intracellular B. cenocepacia are those involved in amino acid transport (Figure 4). Similar findings were reported for other pathogens, which upregulate amino acid transport systems during intracellular growth $[31,34,43]$, suggesting amino acid acquisition from the host may be a general strategy of intracellular bacteria to obtain carbon and nitrogen. However, with nearly $40 \%$ of the genes most affected by internalization falling into the poorly characterized category (Figure 4), it is likely that B. cenocepacia also employs novel survival strategies.

Intracellular bacteria showed decreased expression of genes involved in siderophore-mediated iron acquisition, including those encoding the ornibactin receptor, the transcriptional activator of the pyochelin receptor, and a putative pyochelin biosynthesis protein (Additional file 3, Table S2). Ornibactin contributes to colonization, bacterial persistence, and lung pathology in murine models of acute and chronic lung infection [44]. Ornibactin, however, may not be required for iron uptake by 


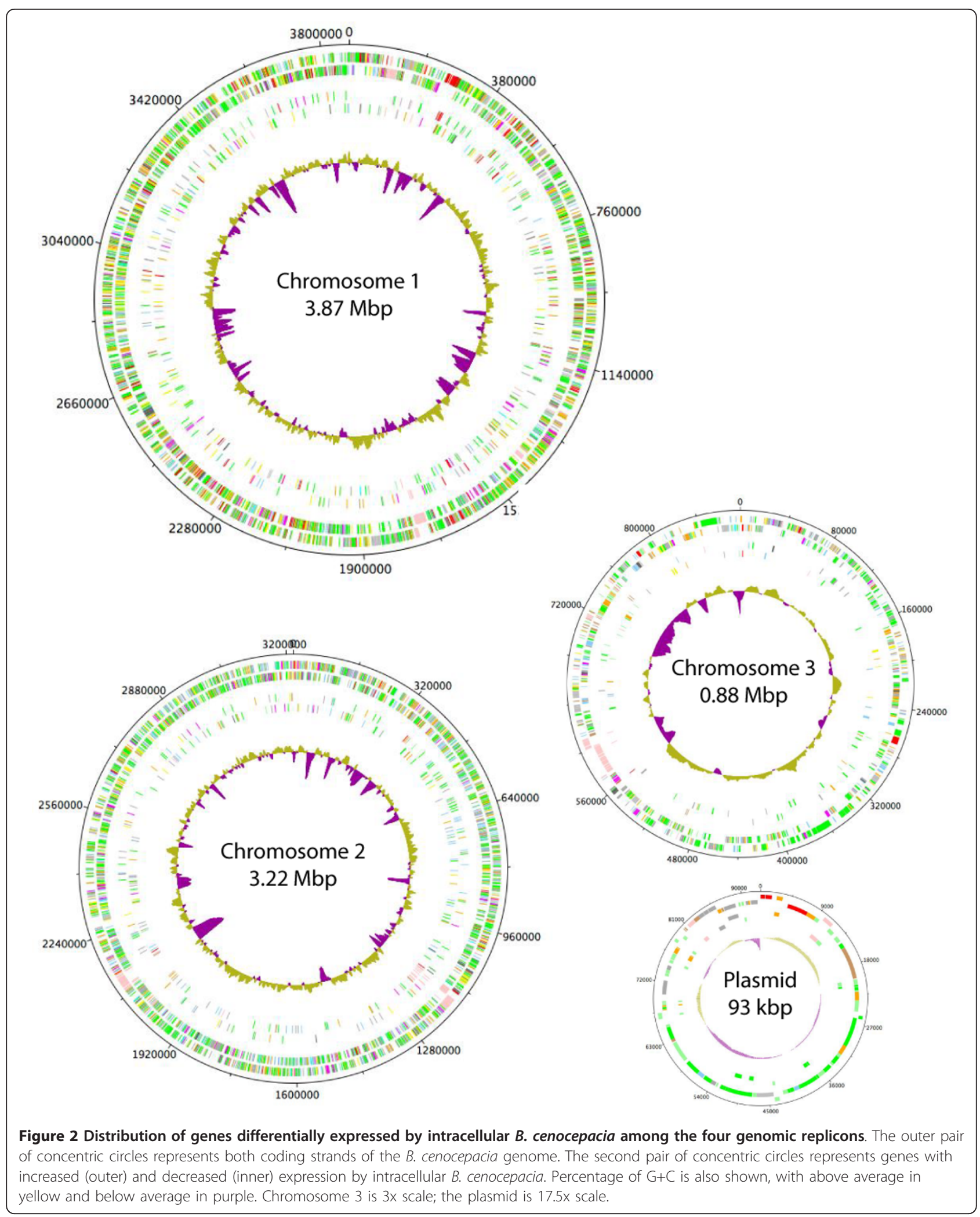




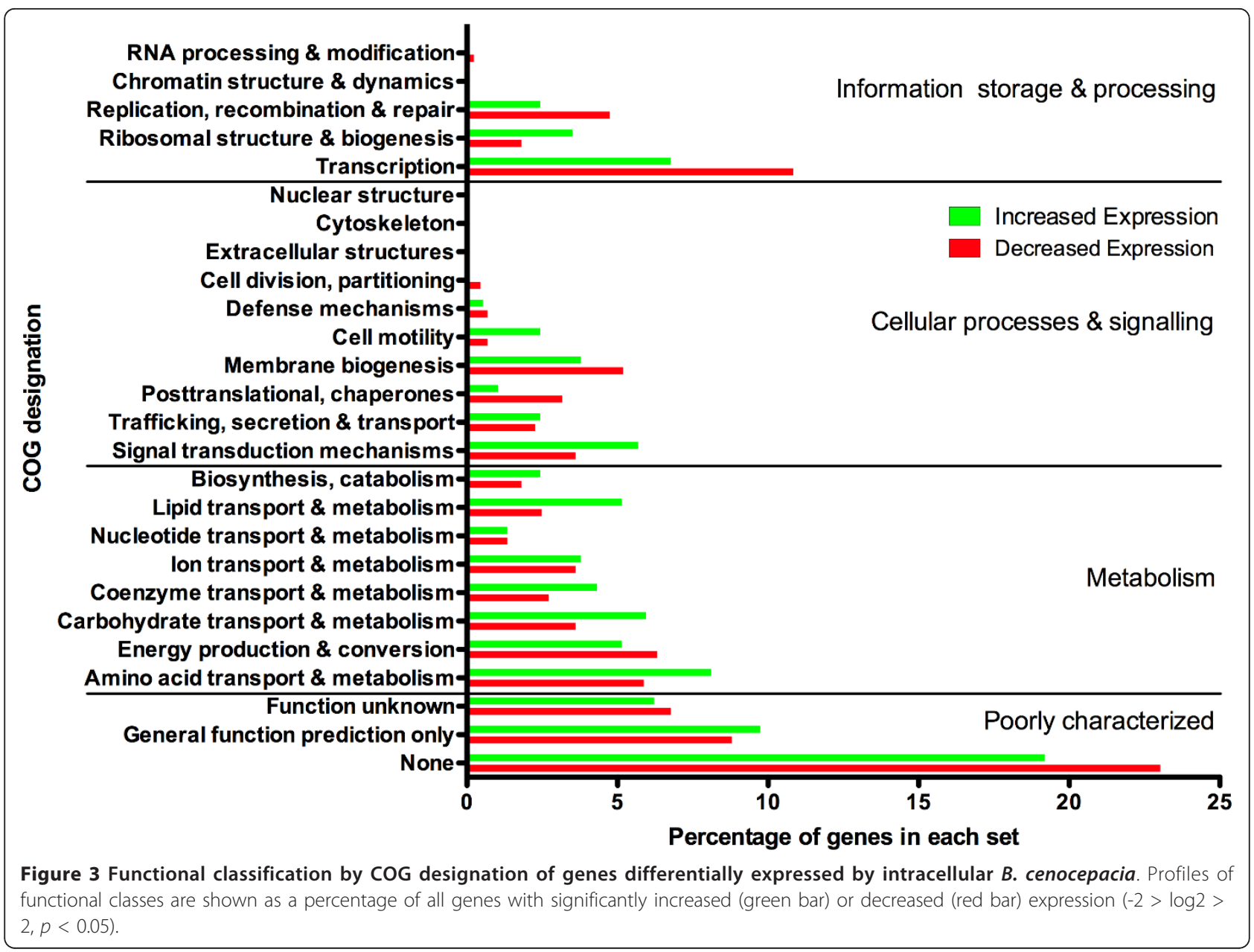

intracellular bacteria, as the phagosome appears to be rich in iron content [45-47].

The large number of genes in the Burkholderia genus, and specifically in B. cenocepacia [18], endows these bacteria with redundant nutrient uptake systems to function under different conditions and perhaps even exploit multiple forms of similar metabolites. Thus, the changes observed in the expression of metabolic genes may reflect the ability of $B$. cenocepacia to utilize resources present in the phagolysosome. Since intracellular bacteria only delay phagolysosomal fusion and reside in a phagosome that remains in contact with the endocytic pathway [21], it would be reasonable to propose that the phagosomal maturation delay allows $B$. cenocepacia to become adapted to survive in low $\mathrm{pH}$ environment. The results of our SCOTS analysis support the notion that intracellular $B$. cenocepacia may adapt to survive in a low $\mathrm{pH}$ environment. Indeed, BCAS0167, one of the two genes encoding the squalene-hopene cyclase for the synthesis of hopanoids, was strongly upregulated by intracellular bacteria. Production of cholesterol-like hopanoids in certain bacteria, including B. cenocepacia [48] contributes to membrane stability under acidic environments $[48,49]$. Furthermore, the upregulation of a putative sodium:solute symporter and a $\mathrm{Na}^{+} / \mathrm{H}^{+}$antiporter suggests that protondriven high-affinity uptake by metabolite:proton symporters is important for intracellular B. cenocepacia to bring nutrients into the cell under acidic conditions [50].

SCOTS-identified genes are involved in bacterial entry, intracellular replication, and macrophage cytotoxicity Because survival within macrophages may contribute to the pathogenesis of B. cenocepacia, the role of several SCOTS-identified genes in intracellular survival was examined. Ten genes, chosen based on their high intracellular expression by microarray data or identification by competitive enrichment, were selected for deletion in the gentamicin-sensitive $B$. cenocepacia $\mathrm{MH} 1 \mathrm{~K}$. This strain is isogenic with K56-2 but allows intracellular bacterial survival to be assessed via the gentamicin protection assay [30]. The ten deleted genes were: BCAL0124 (subunit of the flagellar regulon master regulator), BCAS0186 (putative acyl 


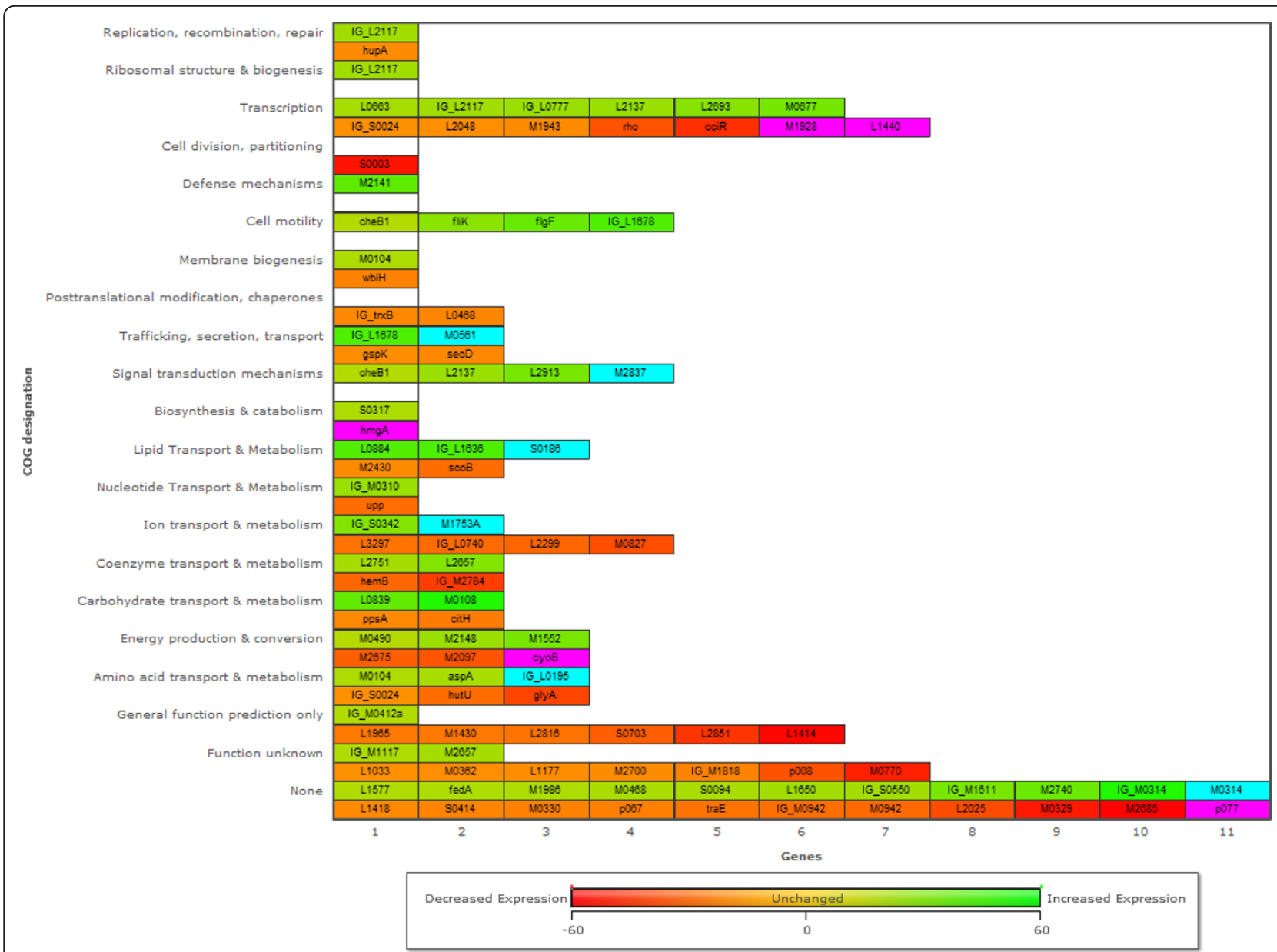

Figure 4 Relative expression of genes with the greatest fold-change in intracellular B. cenocepacia. Heat map shows the 100 genes with the greatest \pm fold-change $(p<0.05)$ in expression in intracellular bacteria relative to non-macrophage-exposed bacteria. Color scale from -60 to +60 -fold change is indicated, with expression increased $>60$-fold in blue, and decreased $>60$-fold in purple. "BCA" has been omitted from gene names.

carrier protein phosphodiesterase), BCAM0434-5, (cation efflux system), BCAM2837 (response regulator component of a two-component regulatory system), BCAL1726 (putative oxidoreductase), BCAM0276 (putative universal stress protein), BCAM0411 (MgtC family protein), BCAL0340 (putative lipoprotein), BCAM1679, (putative lysylphosphatidylglycerol synthetase), and BCAM2446 (putative outer membrane porin).

The ability of mutant strains to enter and replicate within macrophages was assessed relative to the parental strain. Only BCAL0124 $(p<0.01)$ and BCAM0411 $(p<$ $0.05)$ showed statistically significant defects in macrophage entry, while deletion of BCAL1726 resulted in a significant increase in macrophage entry $(p<0.001)$ (Figure 5A). None of the deletions negatively affected intracellular survival, but deletions in BCAL0340 and BCAM0411 increased the ability of the bacteria to replicate intracellularly (Figure 5B). With the exception of $\triangle B C A L 1726$, statistically significant differences in entry and intracellular survival could be complemented by introducing the deleted gene encoded in a plasmid under the control of a constitutive promoter (Figure 5C-D). The lack of complementation of $\triangle B C A L 1726$ suggests the possibility of a secondary mutation. Alternatively, because BCAL1726 is predicted to be the first in a four-gene operon, the deletion may affect downstream genes, thereby preventing possible complementation by BCAL1726 alone.

The results of the gentamicin protection assay may be misleading if the survival of the host cell is not considered, as bacterial cytotoxicity causing membrane damage to the host cell would allow entry of the antibiotic and result in the killing of intracellular bacteria. The viability of Burkholderia-infected macrophages was assayed by flow cytometry using the impermeant fluorescent dye 7AAD, which binds DNA only in macrophages with permeabilized membranes. Macrophages were infected with 


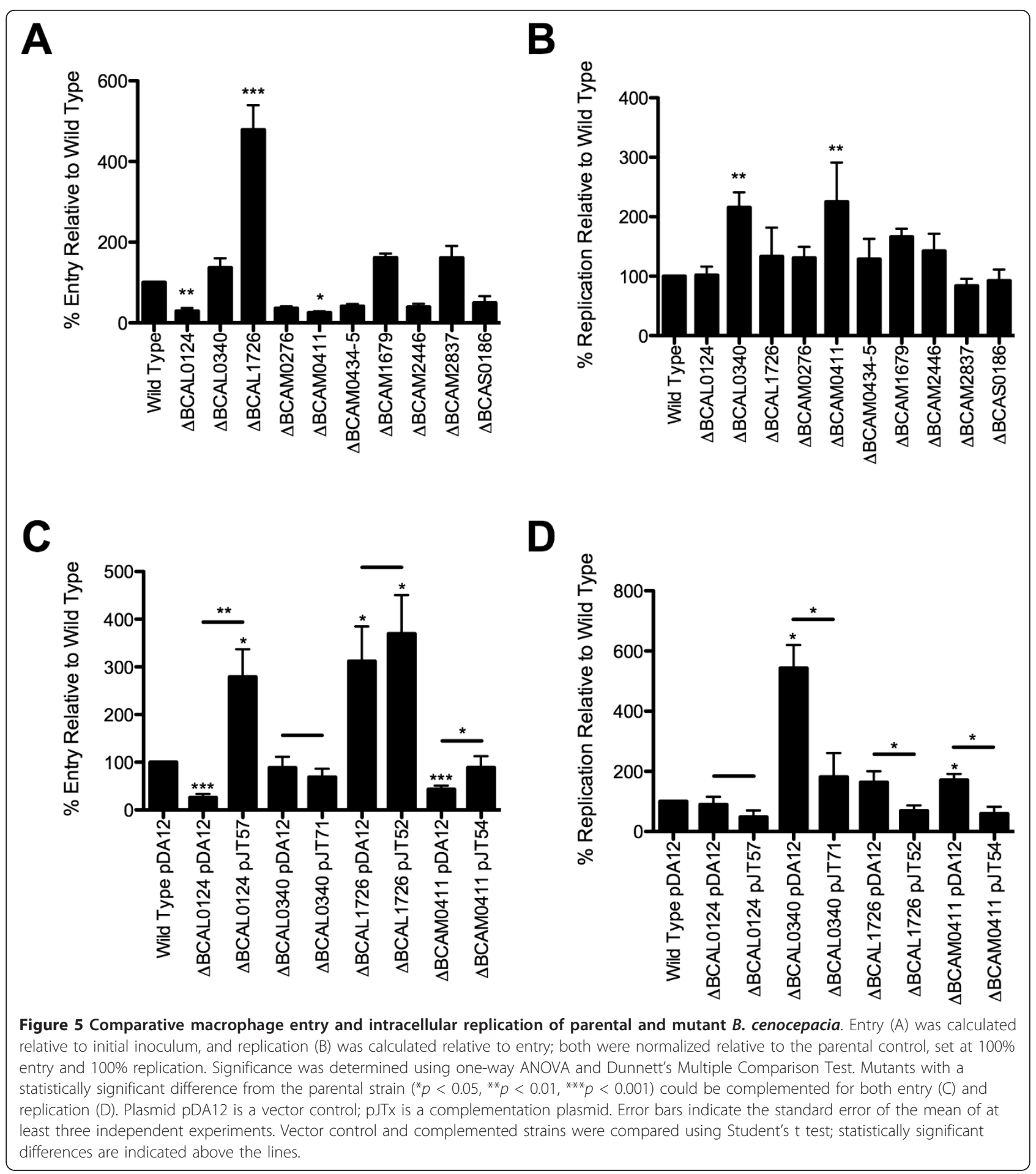

GFP-expressing bacteria and assessed on three different parameters: entry, cytotoxicity, and spread. Parental $B$. cenocepacia was found in $3 \%$ of all macrophages, and was cytotoxic to macrophages at a $1: 1$ ratio, killing approximately $3 \%$ of all cells (Figure 6A). The only mutant displaying statistically significant differences from the parental isolate was $\triangle B C A M 2837$; despite infecting nine-fold better than the parental isolate, $\triangle B C A M 2837$ was also cytotoxic at a $1: 1$ ratio, killing $27 \%$ of all macrophages. Some mutants, including $\triangle B C A M 0276$ and $\triangle B C A M 2446$, appeared to prevent permeabilization of the macrophage membrane, decreasing 

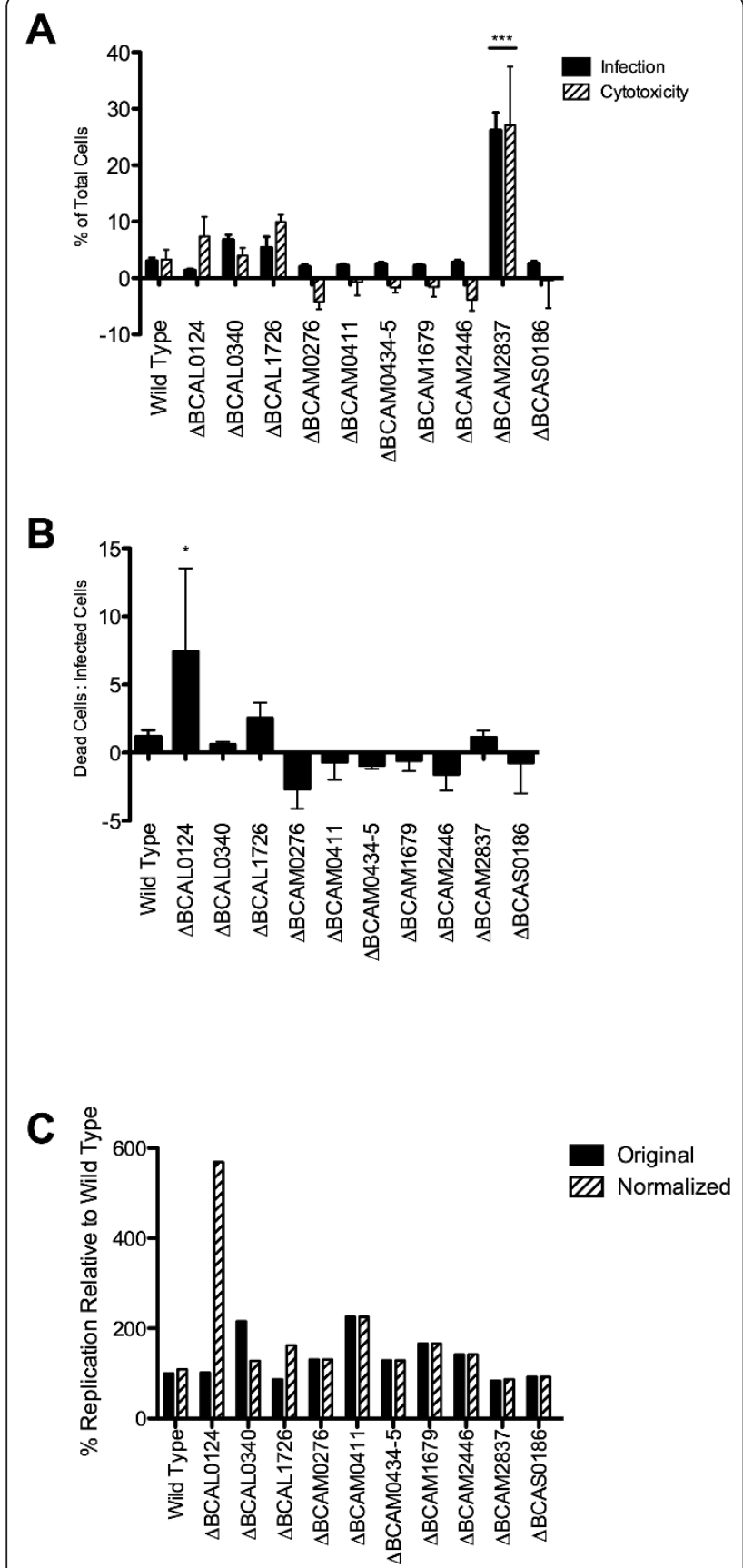

Figure 6 Comparative bacterial infection, host cytotoxicity, and normalized replication of parental and mutant $B$. cenocepacia. Bacterial infection and cytotoxicity (A) are shown as a percentage of total cells. Cytotoxicity was normalized against cell death in uninfected cells. 50000 cells were counted in each of three independent experiments. Standard error bars are indicated. Significance was determined using one-way ANOVA and Dunnett's Multiple Comparison Test. Mutants demonstrating significant difference from the wild-type are indicated $\left({ }^{*} p<0.05,{ }^{* *} p<0.01\right.$, $\left.{ }^{* * *} p<0.001\right)$. The ratio of dead cells: infected cells (B) was used to correct intracellular replication determined by the gentamicin protection assay to give the total expected ratio of intracellular bacteria in the absence of cell death (C). Mutants with a ratio in (B) less than zero are unchanged in (C). cytotoxicity below the level seen in uninfected macrophages (Figure 6A). Of the ten mutants, only four were cytotoxic, defined as permeabilization of the host cellular membrane greater than seen in uninfected cells. The normalization of intracellular replication quantified by the gentamicin protection assay against the rate of cytotoxicity quantified by flow cytometry provided a better overall assessment of the potential role of the genes examined in our study. Normalization revealed significant intracellular replication by $\triangle B C A L 0124$ (Figure 6C). Normalization also showed that $\triangle B C A L 0340$ replicates at a rate similar to the parental isolate, but is protected from gentamicin because it is less cytotoxic. In contrast, $\triangle B C A L 1726$ is more cytotoxic than the parental strain (Figure 6C), and, despite initially infecting at a higher level, has likely been killed by gentamicin entering dying host cells. Mutants that displayed a cytotoxic ratio (Figure 6B) less than zero were not normalized, as in the absence of membrane permeability defects, intracellular bacteria would not be inhibited by gentamicin.

Flow cytometry also permitted investigation of possible intercellular spread of B. cenocepacia in an unchecked infection. After killing extracellular bacteria, infected macrophages were maintained in antibiotic-free media. Under these conditions any bacteria escaping the macrophage would be able to infect neighboring macrophages. The results of this experiment showed that the number of macrophages infected with the parental strain increased six-fold (Figure 7), suggesting that B. cenocepacia was able to escape the macrophage and be engulfed by neighboring macrophages. With the exception of $\triangle B C A M 2837$, the mutant strains spread at least as well as the parental isolate; both $\triangle B C A L 1726$ and $\triangle B C A M 1679$ showed significantly increased spread relative to the parental strain, more than doubling the number of infected macrophages. The ratio of dead:infected cells generally remained approximately 1:1 in an unchecked infection, suggesting that viable $B$. cenocepacia escaped from dead macrophages rather than by an active process of exocytosis. The two exceptions to this were $\triangle$ BCAL0124, which killed 2.5 cells for every cell infected at the time of analysis, and $\triangle$ BCAM2837, which killed only $30 \%$ of infected cells.

The phenotypes seen in individual gene deletions underscore several of the trends seen in the global characterization of intracellular gene expression. The importance of cellular motility suggested by the upregulation of such genes by intracellular bacteria is supported by the phenotypes seen in $\triangle$ BCAL0124 and $\triangle B C A M 2837$. BCAL0124 encodes FlhD, a subunit of the flagellar regulon master regulator necessary for expression of the flagellar structural components [51]. BCAM2837, a pseudogene in sequenced type strain $\mathrm{J} 2315$, is annotated as the response regulator component of a two-component regulatory system. Bioinformatic analysis shows that the protein consists 


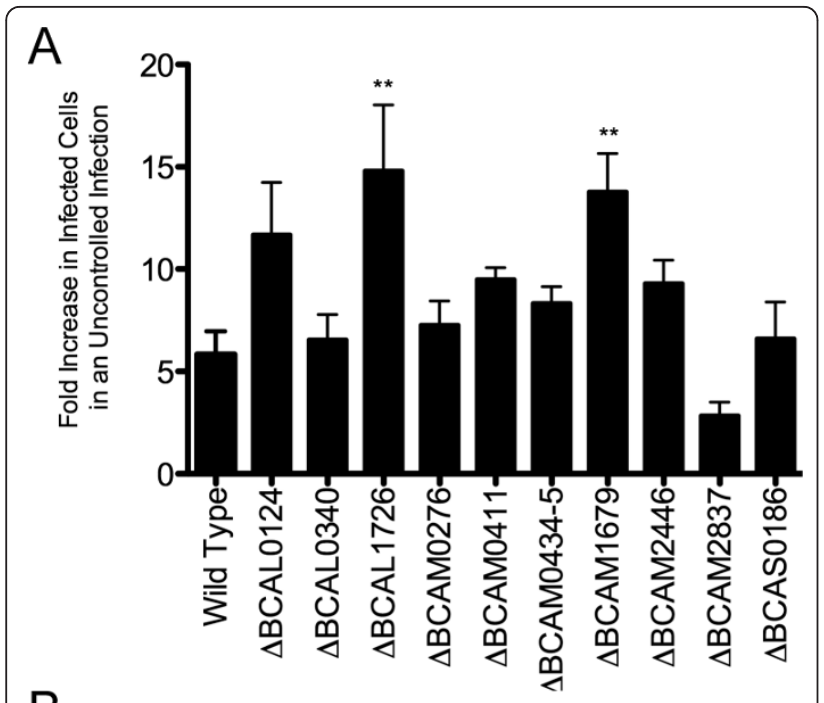

B

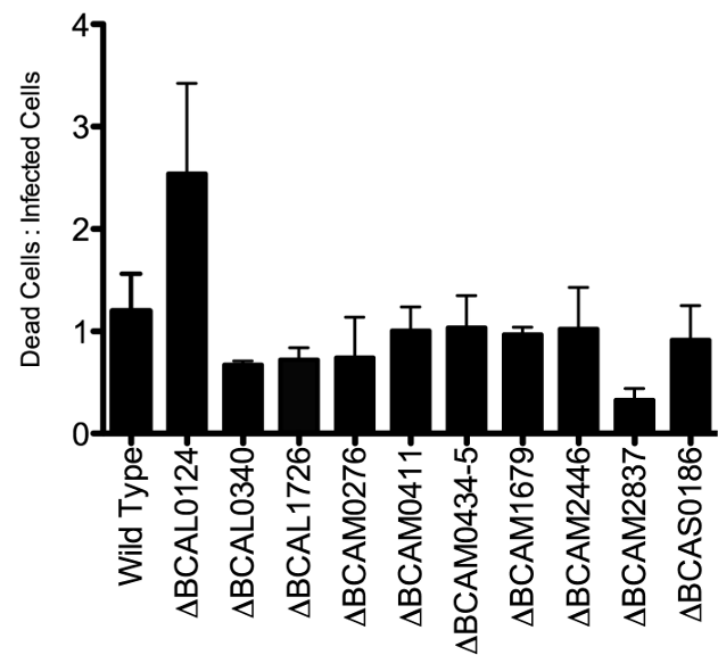

Figure 7 Spread of B. cenocepacia and host cytotoxicity in an unchecked infection of murine macrophages. Capacity to spread (A) is calculated as the fold-increase in infected macrophages when maintained in antibiotic-free media rather than $10 \mu \mathrm{g} / \mathrm{ml}$ gentamicin in the same experiment. Host cytotoxicity (B) is calculated as the ratio of total dead cells to infected cells. 50000 cells were counted in each of three independent experiments. Standard error bars are indicated. Significance was determined using one-way ANOVA and Dunnett's Multiple Comparison Test. Mutants demonstrating significant difference from the wild-type are indicated $\left({ }^{*} p<0.05,{ }^{* *} p<0.01,{ }^{* * *} p<0.001\right)$.

of two distinct domains, one homologous to the chemotaxis protein $\mathrm{CheC}$, and the second homologous to the response regulator CheY. Che proteins are typically involved in chemotaxis [52], where $\mathrm{CheC}$ is a phosphatase that dephosphorylates CheY [53]. The genetic organization of BCAM2837 suggests that this gene is cotranscribed with genes encoding putative diguanylate cyclase and histidine kinase proteins. B. cenocepacia carries three other che $Y$ homologues [54,55], which are expressed in intracellular bacteria while there is one cheC-like gene,
BCAL0136, which is not well expressed intracellularly. Therefore, we speculate that the product of BCAM2837 is part of a complex signal transduction cascade required for bacteria to move away from the phagocytic cell, which may also affect bacterial escape from dying macrophages. The mutant strain lacking BCAL0124 is non-motile, while $\triangle B C A M 2837$ is capable of swimming, but is defective in swarming (Additional file 6, Figure S3). The two mutants are significantly different in their uptake by macrophages, suggesting that the presence of flagella may be important to stimulate phagocytosis. Loss of the bacterial flagella through deletion of $f l i C D$ also results in a severe defect in bacterial internalization by macrophages (Additional file 7 , Figure S4). The requirement of flagellin for efficient macrophage engulfment was previously noted in $B$. pseudomallei [56] and P. aeruginosa [57]. In contrast, bacteria with a motility defect may lose the ability to actively evade phagocytosis, resulting in increased uptake as seen in $\triangle B C A M 2837$. The two mutants also vary in their rates of intracellular replication, host cytotoxicity, and cell spread. B. cenocepacia lacking flagellin is unable to activate $\mathrm{NF} \kappa \mathrm{B}$ or elicit secretion of IL-8 through TLR signaling [58]. Therefore, it is possible that $\triangle$ BCAL0124 bacteria avoid activation of classical proinflammatory signaling cascades, allowing undetected intracellular replication until overwhelming the macrophage and escaping to re-infect neighboring cells. In contrast, the decreased ability to spread and lower cytotoxicity suggest that $\triangle B C A M 2837$ may kill and escape macrophages more slowly, potentially resulting from a defect in swarming motility. The importance of the flagella to the interaction between $B$. cenocepacia and macrophages is not unique, as upregulation of flagellar genes is also seen in intracellular L. pneumophila [31].

Genes involved in membrane biogenesis and modification, as well as trafficking across the membrane were highly regulated by intracellular bacteria (Figure 3). General systems involved in the biogenesis of membrane proteins such as the first gene of the Tat system, several genes in the Sec system, and the signal recognition particle RNA showed decreased expression by intracellular bacteria. In contrast, increased expression of T6SS genes was seen in intracellular bacteria. Deletion of BCAL0340, encoding a putative lipoprotein central to the T6SS cluster, promotes replication of intracellular bacteria (Figure 5) but does not inactivate the T6SS, as evidenced by the appearance of actin-rich protrusions in infected macrophages, a typical phenotype of a functionally active T6SS. In a previous study, three transposon mutants within the T6SS cluster showed attenuated survival in an in vivo rat model of chronic lung infection [38], corroborating the importance of a functional T6SS to infection. Genes involved in modification of the membrane were also highly expressed by intracellular bacteria. BCAM1679 encodes a putative lysylphosphatidylglycerol (Lys-PG) synthetase which adds 
lysine to PG, thereby lowering the net negative charge of the cellular envelope, already lowered in B. cenocepacia by the constitutive presence of 4-amino-4-deoxy-L-arabinose linked to lipid A [59]. Lys-PG may also decrease permeability to cations and protons by raising the surface potential of the membrane, increase membrane fluidity, inhibit genomic DNA replication, and decrease activity of the host defense factor phospholipase A2 (PLA2) (reviewed in [60]). Deletion of BCAM1679 caused extensive spread in an unchecked infection (Figure 7). Since secreted PLA2 can hydrolyze the membrane of cells undergoing early stages of apoptosis [61], it is possible that macrophages infected with $\triangle B C A M 1679$ undergo apoptosis and intracellular bacteria could escape from apoptotic cells to reinfect neighboring cells.

Previous studies have demonstrated that B. cenocepacia is cytotoxic to epithelial cells [62-64] and causes necrosis of dendritic cells [65]. Our results indicate that the same is true for macrophages. The mechanism of macrophage cell death induction by $B$. cenocepacia is under investigation in our laboratory $[66,67]$. Pilinmediated apoptosis induced by $B$. cenocepacia in infected epithelial cells has been documented and shown to depend on the bacterial load [62]. However, production of IL-1 $\beta$ by infected macrophages indicates inflammasome-mediated caspase- 1 activation, which can lead to pyroptosis [67]. Pyroptosis also induces lysosome exocytosis, whereby any bacteria residing within a lysosome are freely delivered to the extracellular milieu as the lysosome fuses with the macrophage plasma membrane, which would explain the mechanism of bacterial release and reinfection of neighboring macrophages.

\section{Conclusions}

Our results indicate that the intracellular survival of B. cenocepacia in macrophages is associated with profound changes in metabolic activity and motility rather than the expression of more traditional "virulence-specific" genes. These observations are consistent with the ability of B. cenocepacia to adapt and survive in a broad range of niches. Our data also show that the delay of phagosomal maturation provides sufficient time for intracellular bacteria to undergo changes in gene expression that likely provide a growth advantage in the phagolysosomal compartment. Therefore, B. cenocepacia is an opportunistic pathogen with the capacity to adapt to survive intracellularly until bacteria can escape back to the extracellular milieu.

\section{Methods}

Bacterial strains, plasmids, media, and growth conditions Bacterial strains and plasmids used in this study are listed in Table 1. Bacteria grew at $37^{\circ} \mathrm{C}$ in Luria-Bertani (LB; Difco) broth with agitation or on LB plates with $1.6 \%$
Bacto agar. Escherichia coli cultures were supplemented as required with $20 \mu \mathrm{g} / \mathrm{ml}$ tetracycline, $50 \mu \mathrm{g} / \mathrm{ml}$ trimethoprim, and $40 \mu \mathrm{g} / \mathrm{ml}$ kanamycin; B. cenocepacia cultures were supplemented as required with $100 \mu \mathrm{g} / \mathrm{ml}$ tetracycline and $100 \mu \mathrm{g} / \mathrm{ml}$ trimethoprim. Plasmids were conjugated into B. cenocepacia by triparental mating at $37^{\circ} \mathrm{C}$ using E. coli DH5 $\alpha$ carrying the helper plasmid pRK2013 [68]. E. coli donor and helper strains were selected against with gentamicin $(50 \mu \mathrm{g} / \mathrm{ml})$ or ampicillin $(100 \mu \mathrm{g} / \mathrm{ml})$ and polymyxin $B(25 \mu \mathrm{g} / \mathrm{ml})$.

\section{Molecular techniques}

DNA manipulations were performed as in [69]. DNA was amplified by PCR in a PTC-221 DNA engine (MJ Research) with Taq DNA polymerase or HotStar DNA polymerase (Qiagen). Amplification of B. cenocepacia DNA was aided by including the Qiagen Q solution. DNA sequencing was performed at the York University Core Molecular Biology and DNA Sequencing Facility in Toronto, Ontario, Canada. Restriction enzymes, T4 DNA ligase (Roche Diagnostics) and Antarctic alkaline phosphatase (New England Biolabs) were used as recommended by manufacturers. Transformation of E. coli SY327 and DH5 $\alpha$ was done by the calcium chloride protocol [70].

\section{Cell culture and infection}

Macrophage cell lines (Table 1) were maintained in Dulbecco's modified Eagle medium (DMEM; Wisent) supplemented with $10 \%$ fetal bovine serum (FBS; Wisent) at $37^{\circ} \mathrm{C}$ in a $95 \%$ humidified atmosphere with $5 \% \mathrm{CO}_{2}$. For macrophage infection, cells were seeded in a 12-well plate at 1.25 $\times 10^{5}$ cells per well or a 6 -well plate at $2.5 \times 10^{5}$ cells per well and grown $15 \mathrm{~h}$. Bacterial cultures grown at $37^{\circ} \mathrm{C}$ for $16 \mathrm{~h}$ were washed twice and resuspended in DMEM-10\% FBS. Macrophage monolayers were washed with phosphate-buffered saline (PBS; Wisent). Bacteria were added at a multiplicity of infection (MOI) of $50: 1$ or $10: 1$ in 1-2 $\mathrm{ml}$ DMEM-10\% FBS. Plates were centrifuged $1 \mathrm{~min}$ at $300 \times g$ and incubated at $37^{\circ} \mathrm{C}, 95 \%$ humidity and $5 \% \mathrm{CO}_{2}$.

\section{RNA extraction, cDNA synthesis, and amplification}

RNA was extracted from two 6-well plates containing equal numbers of $B$. cenocepacia, differing only in the presence (intracellular (I) RNA) or absence (non-macrophage-exposed RNA) of macrophages. At $4 \mathrm{~h}$ postinfection, macrophage monolayers were washed three times with PBS and lysed in $1 \mathrm{ml}$ cold deionized $\mathrm{H}_{2} \mathrm{O}$. Non macrophage-exposed bacteria were resuspended and collected. For each condition, cells from 6 wells were resuspended in $1 \mathrm{mg} / \mathrm{ml}$ lysozyme (Roche). Total RNA was extracted using TRIzol (Invitrogen) and treated with RNase-free DNase (Roche) according to the manufacturer's instructions. RNA purity, integrity, and concentration were determined by PCR, agarose gel electrophoresis, 
Table 1 Strains, plasmids, and cell lines used in this study

\begin{tabular}{|c|c|c|}
\hline Strain, cell line, or plasmid & Relevant characteristics $^{\mathrm{a}}$ & Source or reference \\
\hline \multicolumn{3}{|l|}{ Escherichia coli } \\
\hline $\mathrm{DH} 5 \alpha$ & $\mathrm{F}^{-}, \phi 80$ lacZ DM15 $\triangle\left(\right.$ lacZYA-argF)U169 endA1 recA1 hsdR17 $\left(\mathrm{r}_{\mathrm{K}}^{-} \mathrm{m}_{\mathrm{K}}^{+}{ }^{+}\right)$supE44 thi-1 $\triangle 9 y \mathrm{rA96}$ relA1 & Laboratory stock \\
\hline SY327 & $\operatorname{araD} \Delta($ lac pro) $\arg E(A m)$ recA56 rifr nalA, $\lambda$ pir & {$[75]$} \\
\hline \multicolumn{3}{|l|}{ Burkholderia cenocepacia } \\
\hline$J 2315$ & Epidemic strain ET12 clone, CF clinical isolate & P.A. Sokol \\
\hline $\mathrm{K} 56-2$ & Epidemic strain ET12 clone, CF clinical isolate & $\mathrm{BCRRC}^{\mathrm{b}}$ \\
\hline $\mathrm{MH} 1 \mathrm{~K}$ & K56-2 $\triangle$ BCAL1674-6 & {$[30]$} \\
\hline JST19 & MH1K $\triangle B C A L 0124$ & This study \\
\hline JST71 & MH1K $\triangle \mathrm{BCAS0186}$ & This study \\
\hline JST75 & MH1K $\triangle B C A M 2837$ & This study \\
\hline JST128 & MH1K $\triangle B C A L 1726$ & This study \\
\hline JST130 & MH1K $\triangle \mathrm{BCAM0276}$ & This study \\
\hline JST132 & MH1K $\triangle B C A M 0411$ & This study \\
\hline JST134 & MH1K $\triangle B C A M 2446$ & This study \\
\hline JST136 & MH1K $\triangle \mathrm{BCAM0434-5}$ & This study \\
\hline JST190 & MH1K $\triangle B C A L 0340$ & This study \\
\hline JST194 & MH1K $\triangle B C A M 1679$ & This study \\
\hline \multicolumn{3}{|l|}{ Macrophage cell lines } \\
\hline ANA-1 & C57BL/6 murine bone marrow-derived macrophages & {$[76]$} \\
\hline RAW 264.7 & BALB/C murine macrophage cell line & ATCC $^{C}$ \\
\hline \multicolumn{3}{|l|}{ Plasmid } \\
\hline pDA12 & ori $_{P B B R 1}$, Tet $^{R}, m o b^{+}, P_{d h f r}$ & [28] \\
\hline pDA42 & pDA12, eGFP & {$[28]$} \\
\hline pDAl-Scel-SacBN & ori $_{P B B R l}$, Tet $^{R}, m_{o b}, P_{d h f r}, s a c B$, encodes I-Scel endonuclease & [30] \\
\hline pDelbcsM & pGPI-Scel with regions flanking BCAL0340 & {$[77]$} \\
\hline pGPI-Scel & ori $_{R \sigma k}, T p^{R}, m o b^{+}$, carries I-Scel cut site & [74] \\
\hline pJT25 & pUC19 with K56-2 rDNA $(23 \mathrm{~S}, 16 \mathrm{~S}, 5 \mathrm{~S}), \mathrm{Ap}^{\mathrm{R}}$ & This study \\
\hline $\mathrm{pJT31}$ & pGPI-Scel with regions flanking BCAL0124 & This study \\
\hline $\mathrm{pJT41}$ & pGPI-Scel with regions flanking BCAS0186 & This study \\
\hline $\mathrm{pJT42}$ & pGPI-Scel with regions flanking BCAM2837 & This study \\
\hline $\mathrm{pJT} 45$ & pGPI-Scel with regions flanking BCAL1726 & This study \\
\hline $\mathrm{pJT46}$ & pGPI-Scel with regions flanking BCAM0276 & This study \\
\hline $\mathrm{pJT47}$ & pGPI-Scel with regions flanking BCAM0411 & This study \\
\hline $\mathrm{pJT} 48$ & pGPI-Scel with regions flanking BCAM2446 & This study \\
\hline $\mathrm{pJT} 49$ & pGPI-Scel with regions flanking BCAM0434-5 & This study \\
\hline $\mathrm{pJT52}$ & pDA12, BCAL1726 & This study \\
\hline $\mathrm{pJT54}$ & pDA12, BCAM0411 & This study \\
\hline $\mathrm{pJT57}$ & pDA12, BCAL0124 & This study \\
\hline $\mathrm{pJT71}$ & pDA12, BCAL0340 & This study \\
\hline $\mathrm{pJT72}$ & pGPI-Scel with regions flanking BCAM1679 & This study \\
\hline pRK201 & RK2 derivative, $\mathrm{Km}^{\mathrm{R}}, \mathrm{mob}^{+}$, tra $^{+}$, ori $i_{\text {colE1 } 1}$ & {$[68]$} \\
\hline pUC19 & ori $_{p M B 1}, \mathrm{Ap}^{\mathrm{R}}, \mathrm{mob}^{+}, P_{\text {lac }}$ & {$[78]$} \\
\hline
\end{tabular}

${ }^{a} \mathrm{Tp}$, trimethoprim; Tet, tetracycline; Ap, ampicillin; Km, kanamycin

${ }^{\mathrm{b}}$ B. cepacia complex Research and Referral Repository for Canadian CF Clinics

c American Type Culture Collection

and $\mathrm{A}_{260} / \mathrm{A}_{280}$ spectrophotometer readings, respectively. $\mathrm{A}$ $5 \mu \mathrm{g}$ RNA sample from each condition ("intracellular" and "non macrophage-exposed") was converted to first-strand cDNA by random priming with Transcriptor reverse transcriptase (Roche) according to the manufacturer's specifications. Primers had a defined 5 'terminal sequence and a 3' random nonamer; different terminal sequences were used for intracellular (I-3025) and non macrophageexposed RNA (N-3017) (Additional file 8, Table S4). cDNAs were double-stranded using Klenow fragment 
(Roche) as described in [71]; cDNA libraries were amplified for 25 cycles using defined primers I-3032 (intracellular) or N-3033 (non macrophage-exposed).

\section{Selective capture of transcribed sequences}

The SCOTS protocol was carried out as in [72]. Briefly, $0.3 \mu \mathrm{g}$ of denatured, sonicated, biotinylated B. cenocepacia K56-2 chromosome were mixed with $5 \mu \mathrm{g}$ denatured ribosomal DNA fragments (sonicated pJT25; Table 1) and hybridized $30 \mathrm{~min}$ at $68^{\circ} \mathrm{C}$ to pre-block rRNAencoding DNA regions. $3 \mu \mathrm{g}$ of cDNA were denatured and re-annealed $30 \mathrm{~min}$ at $68^{\circ} \mathrm{C}$ to remove abundant transcripts. cDNA and chromosomal DNA were combined and hybridized $24 \mathrm{~h}$ at $68^{\circ} \mathrm{C}$. Chromosome-cDNA hybrids were removed from solution with streptavidincoated magnetic beads (Invitrogen). Captured cDNA was eluted, precipitated, and amplified using library-specific defined primers (Additional file 8, Table S4). For each condition, 10 parallel first-round reactions were done to maximize the cDNA sample diversity; the resultant cDNA was pooled for each condition and two subsequent rounds of SCOTS carried out. The final cDNA libraries were used both for competitive enrichment hybridization and as probes for $B$. cenocepacia microarrays.

\section{Competitive enrichment}

To preferentially enrich for intramacrophage-expressed transcripts, $0.3 \mu \mathrm{g}$ of B. cenocepacia K56-2 chromosome was pre-blocked with both 5- $\mu \mathrm{g}$ rDNA and $10 \mu \mathrm{g}$ of denatured triple-SCOTS enriched non macrophage-exposed cDNA (above). $3 \mu \mathrm{g}$ of triple-SCOTS enriched intracellular cDNA (above) was denatured and re-annealed $30 \mathrm{~min}$ at $68^{\circ} \mathrm{C}$ to remove abundant transcripts. cDNA and blocked chromosomal DNA were combined and hybridized $18 \mathrm{~h}$ at $68^{\circ} \mathrm{C}$. Chromosome-cDNA hybrids were removed from solution with streptavidin-coated magnetic beads. Captured cDNA was eluted, precipitated, and amplified using intracellular library-specific defined primer I-3032. Following three rounds of enrichment, cDNA were digested with restriction enzyme $\mathrm{XbaI}$, cloned into $\mathrm{XbaI}$-digested, dephosphorylated pUC19, and transformed into E. coli DH5 $\alpha$. Individual cDNA inserts were screened by Southern blot for hybridization to DIG-labeled cDNA libraries. cDNA that hybridized to intracellular cDNA, but not to non macrophage-exposed cDNA, were sequenced and identified by BLAST analysis.

\section{Microarray experimental design and analysis}

SCOTS cDNA or B. cenocepacia J2315 genomic DNA was labeled with CyScribe ${ }^{\mathrm{TM}}$ Array CGH Labeling Kit (GE Healthcare) according to the manufacturer's protocols. SCOTS cDNA was labeled with Cy5 and genomic DNA with $\mathrm{Cy} 3$; cDNA samples were mixed, hybridized to custom B. cenocepacia microarrays (Agilent) according to the Agilent 60-mer oligonucleotide microarray processing protocol, and scanned. Labeling of cDNA, hybridization, and scanning of arrays were performed by the Mahenthiralingam Laboratory, Cardiff University, Wales. Microarray data analysis was done using GeneSpring GX 7.3.1 (Agilent). Raw data was preprocessed via the enhanced Agilent FE import prior to per-spot and per-chip normalizations for each array. Feature intensity varied across the six arrays. Statistical analysis between intracellular and nonmacrophage-exposed conditions was performed using a paired Student's $t$-test; genes were considered differentially expressed at an intracellular:non macrophage-exposed ratio of \pm 2 -fold with a $p<0.05$.

The microarray dataset has been deposited in the ArrayExpress database http://www.ebi.ac.uk/arrayexpress/ under accession number E-MEXP-3408.

\section{Quantitative reverse transcriptase PCR (qRT-PCR)}

To validate microarray data, five genes with altered expression (4 upregulated: BCAM0314, BCAM2141, BCAM0276, and BCAS0186; and 1 downregulated: BCAM1928) were examined individually using qPCR. Sigma factor gene rpoD (BCAM0918) was used as a reference gene. Oligonucleotide primers for each gene (Additional file 8, Table S4) were designed with Primer3 [73]. Total RNA was isolated as described above. cDNA was synthesized using random hexamers (Invitrogen) and Transcriptor reverse transcriptase. Quantitation and melting curve analyses for qPCR were performed using the Rotor Gene 6000 (Corbett Life Science) with FastStart SYBR Green (Roche) according to the manufacturer's instructions. Expression of the target gene was normalized to the reference gene for each condition, allowing intercondition comparison. Data shown are representative of at least two independent experiments.

\section{Mutagenesis of B. cenocepacia K56-2}

The I-SceI homing endonuclease system was used to construct unmarked deletions of genes or gene clusters in B. cenocepacia K56-2 [74]. Briefly, regions flanking the gene or genes to be deleted were amplified with gene-specific primers containing restriction sites (Additional file 8, Table S4). Upstream amplicons were digested with restriction enzymes $\mathrm{XbaI}$-ClaI; downstream amplicons were digested with ClaI-EcoRI. Both upstream and downstream amplicons were cloned into XbaI-EcoRI digested, de-phosphorylated pGPI-SceI, giving rise to mutagenesis plasmids (Table 1). Mutagenesis plasmids were introduced into either B. cenocepacia K56-2 or MH1K by triparental mating. Plasmid pDAI-SceI-SacBN, encoding the homing endonuclease, was conjugated into single crossover mutants, causing a double-strand break resolved by either a second crossover, yielding mutant genotype, or by 
reversion to wild-type. Exconjugants were screened by PCR, and confirmed mutants were plated on LB with $5 \%$ sucrose to cure pDAI-SceI-SacBN. PCR confirmed that the deletion had occurred, yielding gentamicin-sensitive mutants (Table 1).

\section{Complementation experiments}

To complement single gene deletions, wild-type genes were PCR amplified from B. cenocepacia K56-2 with gene-specific primers (Additional file 8, Table S4) and the following thermal cycling conditions: $95^{\circ} \mathrm{C}$ for $5 \mathrm{~min}$ utes, 30 cycles of $95^{\circ} \mathrm{C}$ for $45 \mathrm{~s}, 60^{\circ} \mathrm{C}$ for $45 \mathrm{~s}$, and $72^{\circ} \mathrm{C}$ for $90 \mathrm{~s}$, and a final extension at $72^{\circ} \mathrm{C}$ for $10 \mathrm{~min}$. The resulting amplicon was digested with restriction enzymes $\mathrm{XbaI}$ and NdeI, and ligated into $\mathrm{XbaI} / \mathrm{NdeI}$-digested, dephosphorylated pDA12, giving rise to a complementation plasmid (Table 1), which could be introduced to the mutant strain through conjugation. pDA12 was used as a vector control in all experiments. Statistically significant differences between vector control and complemented strains were determined using Student's t test.

\section{Gentamicin protection assays}

Thirty min post-infection, B. cenocepacia-infected cells were washed three times with PBS and DMEM-50 $\mu \mathrm{g} /$ $\mathrm{ml}$ gentamicin was added to kill extracellular bacteria. After $30 \mathrm{~min}$, the media was replaced with DMEM-10 $\mu \mathrm{g} / \mathrm{ml}$ gentamicin. Infected monolayers were washed with PBS, and lysed with $0.1 \%$ Triton X-100 (Sigma) in PBS at 1 and $24 \mathrm{~h}$ post-infection. Surviving bacteria were enumerated by bacterial plate count (CFU). Bacterial entry was calculated as a percentage of initial inoculum. Intracellular replication was calculated as a percentage of bacterial entry for each strain. To compare between experiments, percentage recovery was normalized against the parental control, set as $100 \%$ entry and replication. Statistical analysis was performed using one-way ANOVA and Dunnett's Multiple Comparison Test.

\section{Flow cytometry}

B. cenocepacia expressing eGFP from the plasmid pDA42 [28] were infected as above in 12-well plates at a multiplicity of 50:1. At $2 \mathrm{~h}$ post-infection cells were washed three times with PBS and DMEM-50 $\mu \mathrm{g} / \mathrm{ml}$ gentamicin was added to kill extracellular bacteria. After $30 \mathrm{~min}$, the medium was replaced with DMEM with and without gentamicin $(10 \mu \mathrm{g} / \mathrm{ml})$. Infected monolayers were washed with PBS, and removed with cold $0.04 \%$ EDTA in PBS at $24 \mathrm{~h}$ post-infection. Cells maintained in media with gentamicin represented initial infection, while cells maintained in antibiotic-free media represented uncontrolled infection. Macrophages were collected by centrifugation for $5 \mathrm{~min}$ at $400 \times g$ and $4^{\circ} \mathrm{C}$. Cells were resuspended in cold PBS with $2.5 \mu \mathrm{g} / \mathrm{ml}$ 7-aminoactinomycin D (7AAD; Invitrogen) and maintained on ice. Samples were enumerated using a FACSCalibur with CellQuest Pro acquisition software (Becton Dickinson). Data analysis was done with FlowJo (Tree Star, Inc.). All results were normalized against uninfected controls. Statistical analysis was performed using one-way ANOVA and Dunnett's Multiple Comparison Test.

\section{Additional material}

\section{Additional file 1: Figure S1-Bacterial transcripts specific to intracellular $B$. cenocepacia can be identified by differential hybridization.}

Additional file 2: Table S1-Intracellular-specific selectively captured sequences.

Additional file 3: Table S2-Genes with significantly higher or lower expression by intracellular $\boldsymbol{B}$. cenocepacia. Genes included show greater than 2 -fold change in expression $(p<0.05)$ in intracellular bacteria relative to non-macrophage-exposed bacteria. The first sheet contains genes with increased intracellular expression, the second genes with decreased intracellular expression.

Additional file 4: Table S3-In vivo essential genes with increased expression in intracellular bacteria.

Additional file 5: Figure S2-Fold change gene expression of selected SCOTS-identified genes measured by qRT-PCR.

Additional file 6: Figure S3- $\triangle B C A L 0124$ and $\triangle B C A M 2837$ are defective in motility.

Additional file 7: Figure S4-Flagellin is necessary for efficient bacterial entry into macrophages.

Additional file 8: Table S4-Oligonucleotide primers used in this study.

\section{Acknowledgements}

The authors thank Dr. Andrea Sass and Dr. Eshwar Mahenthiralingam from Cardiff University, who conducted the microarray hybridization experiments and assisted with data analysis. J.S.T. was supported by scholarships from Cystic Fibrosis Canada and the Canadian Natural Sciences and Engineering Research Council. This work was supported by grants from Cystic Fibrosis Canada. M.A.V. holds a Zeller's senior scientists award from Cystic Fibrosis Canada and a Tier I Canada Research Chair in Infectious Diseases and Microbial Pathogenesis.

\section{Author details}

${ }^{1}$ Infectious Diseases Research Group, Department of Microbiology \& Immunology, University of Western Ontario, London, Ontario, N6A 5C1, Canada. ${ }^{2}$ Department of Medicine, University of Western Ontario, London, Ontario, N6A 5C1, Canada.

\section{Authors' contributions}

JST conceived the project, designed and conducted the experiments, analyzed data, wrote the manuscript, and edited the manuscript. MAV conceived the project, obtained funding for the project, designed the experiments, analyzed data, and edited the manuscript. All authors read and approved the final manuscript.

Received: 18 November 2011 Accepted: 9 February 2012 Published: 9 February 2012

\section{References}

1. Vanlaere E, Baldwin A, Gevers D, Henry D, De Brandt E, LiPuma JJ, Mahenthiralingam E, Speert DP, Dowson C, Vandamme P: Taxon K, a 
complex within the Burkholderia cepacia complex, comprises at least two novel species, Burkholderia contaminans sp. nov. and Burkholderia lata sp. nov. Int J Syst Evol Microbiol 2009, 59(Pt 1):102-111.

2. Vanlaere E, Lipuma JJ, Baldwin A, Henry D, De Brandt E, Mahenthiralingam E, Speert D, Dowson C, Vandamme P: Burkholderia latens sp. nov., Burkholderia diffusa sp. nov., Burkholderia arboris sp. nov., Burkholderia seminalis sp. nov. and Burkholderia metallica sp. nov., novel species within the Burkholderia cepacia complex. Int I Syst Evol Microbiol 2008, 58(Pt 7):1580-1590.

3. Coenye T, Vandamme P: Diversity and significance of Burkholderia species occupying diverse ecological niches. Environ Microbiol 2003, 5(9):719-729.

4. Vial L, Chapalain A, Groleau MC, Deziel E: The various lifestyles of the Burkholderia cepacia complex species: a tribute to adaptation. Environ Microbiol 2011, 13(1):1-12.

5. Holmes A, Govan J, Goldstein R: Agricultural use of Burkholderia (Pseudomonas) cepacia: a threat to human health? Emerg Infect Dis 1998, 4(2):221-227.

6. Krumme ML, Timmis KN, Dwyer DF: Degradation of trichloroethylene by Pseudomonas cepacia G4 and the constitutive mutant strain G4 5223 PR1 in aquifer microcosms. Appl Environ Microbiol 1993, 59(8):2746-2749.

7. Govan JR, Hughes JE, Vandamme P: Burkholderia cepacia: medical, taxonomic and ecological issues. J Med Microbiol 1996, 45(6):395-407.

8. Isles A, Maclusky I, Corey M, Gold R, Prober C, Fleming P, Levison H: Pseudomonas cepacia infection in cystic fibrosis: an emerging problem. J Pediatr 1984, 104:206-210.

9. Corey $M$, Farewell $V$ : Determinants of mortality from cystic fibrosis in Canada, 1970-1989. Am J Epidemiol 1996, 143(10):1007-1017.

10. Waters $V$, Ratjen F: Multidrug-resistant organisms in cystic fibrosis: management and infection-control issues. Expert Rev Anti Infect Ther 2006, 4(5):807-819.

11. Govan JR, Brown PH, Maddison J, Doherty CJ, Nelson JW, Dodd M, Greening AP, Webb AK: Evidence for transmission of Pseudomonas cepacia by social contact in cystic fibrosis. Lancet 1993, 342(8862):15-19.

12. LiPuma JJ, Spilker T, Coenye T, Gonzalez CF: An epidemic Burkholderia cepacia complex strain identified in soil. Lancet 2002, 359(9322):2002-2003.

13. LiPuma JJ, Dasen SE, Nielson DW, Stern RC, Stull TL: Person-to-person transmission of Pseudomonas cepacia between patients with cystic fibrosis. Lancet 1990, 336:1094-1096.

14. Reik R, Spilker T, Lipuma JJ: Distribution of Burkholderia cepacia complex species among isolates recovered from persons with or without cystic fibrosis. J Clin Microbiol 2005, 43(6):2926-2928.

15. Speert DP, Henry D, Vandamme P, Corey M, Mahenthiralingam E: Epidemiology of Burkholderia cepacia complex in patients with cystic fibrosis, Canada. Emerg Infect Dis 2002, 8(2):181-187.

16. Courtney JM, Dunbar KE, McDowell A, Moore JE, Warke TJ, Stevenson M, Elborn JS: Clinical outcome of Burkholderia cepacia complex infection in cystic fibrosis adults. J Cyst Fibros 2004, 3(2):93-98.

17. Baldwin A, Mahenthiralingam E, Drevinek P, Vandamme P, Govan JR, Waine DJ, LiPuma JJ, Chiarini L, Dalmastri C, Henry DA, et al: Environmental Burkholderia cepacia complex isolates in human infections. Emerg Infect Dis 2007, 13(3):458-461

18. Holden MT, Seth-Smith HM, Crossman LC, Sebaihia M, Bentley SD, CerdenoTarraga AM, Thomson NR, Bason N, Quail MA, Sharp S, et al: The genome of Burkholderia cenocepacia J2315, an epidemic pathogen of cystic fibrosis patients. J Bacterio/ 2009, 191(1):261-277.

19. Loutet SA, Valvano MA: A decade of Burkholderia cenocepacia virulence determinant research. Infect Immun 2010, 78(10):4088-4100.

20. Sajjan US, Yang JH, Hershenson MB, LiPuma JJ: Intracellular trafficking and replication of Burkholderia cenocepacia in human cystic fibrosis airway epithelial cells. Cell Microbiol 2006, 8(9):1456-1466.

21. Lamothe J, Huynh KK, Grinstein S, Valvano MA: Intracellular survival of Burkholderia cenocepacia in macrophages is associated with a delay in the maturation of bacteria-containing vacuoles. Cell Microbiol 2007, 9(1):40-53.

22. Martin DW, Mohr CD: Invasion and intracellular survival of Burkholderia cepacia. Infect Immun 2000, 68(1):24-29.

23. Saini LS, Galsworthy SB, John MA, Valvano MA: Intracellular survival of Burkholderia cepacia complex isolates in the presence of macrophage cell activation. Microbiology 1999, 145(Pt 12):3465-3475.

24. Saldias MS, Valvano MA: Interactions of Burkholderia cenocepacia and other Burkholderia cepacia complex bacteria with epithelial and phagocytic cells. Microbiology 2009, 155(Pt 9):2809-2817.
25. Huynh KK, Plumb JD, Downey GP, Valvano MA, Grinstein S: Inactivation of macrophage Rab7 by Burkholderia cenocepacia. J Innate Immun 2010, 2(6):522-533.

26. Keith KE, Hynes DW, Sholdice JE, Valvano MA: Delayed association of the NADPH oxidase complex with macrophage vacuoles containing the opportunistic pathogen Burkholderia cenocepacia. Microbiology 2009, 155(Pt 4):1004-1015.

27. Natale DA, Galperin MY, Tatusov RL, Koonin EV: Using the COG database to improve gene recognition in complete genomes. Genetica 2000, 108(1):9-17.

28. Aubert DF, Flannagan RS, Valvano MA: A novel sensor kinase-response regulator hybrid controls biofilm formation and type $\mathrm{VI}$ secretion system activity in Burkholderia cenocepacia. Infect Immun 2008, 76(5):1979-1991.

29. Tatusov RL, Galperin MY, Natale DA, Koonin EV: The COG database: a tool for genome-scale analysis of protein functions and evolution. Nucleic Acids Res 2000, 28(1):33-36

30. Hamad MA, Skeldon AM, Valvano MA: Construction of aminoglycosidesensitive Burkholderia cenocepacia strains for use in studies of intracellular bacteria with the gentamicin protection assay. Appl Environ Microbiol 2010, 76(10):3170-3176.

31. Faucher SP, Mueller CA, Shuman HA: Legionella pneumophila transcriptome during intracellular multiplication in human macrophages. Front Microbiol 2011, 2:60.

32. Graham JE, Clark-Curtiss JE: Identification of Mycobacterium tuberculosis RNAs synthesized in response to phagocytosis by human macrophages by selective capture of transcribed sequences (SCOTS). Proc Natl Acad Sci USA 1999, 96(20):11554-11559.

33. Daigle F, Graham JE, Curtiss R: Identification of Salmonella typhi genes expressed within macrophages by selective capture of transcribed sequences (SCOTS). Mol Microbiol 2001, 41(5):1211-1222.

34. Faucher SP, Porwollik S, Dozois CM, McClelland M, Daigle F: Transcriptome of Salmonella enterica serovar Typhi within macrophages revealed through the selective capture of transcribed sequences. Proc Natl Acad Sci USA 2006, 103(6):1906-1911.

35. Poirier K, Faucher SP, Beland M, Brousseau R, Gannon V, Martin C, Harel J, Daigle F: Escherichia coli 0157:H7 survives within human macrophages: global gene expression profile and involvement of the Shiga toxins. Infect Immun 2008, 76(11):4814-4822.

36. Emboule L, Daigle F, Meyer DF, Mari B, Pinarello V, Sheikboudou C, Magnone V, Frutos R, Viari A, Barbry P, et al: Innovative approach for transcriptomic analysis of obligate intracellular pathogen: selective capture of transcribed sequences of Ehrlichia ruminantium. BMC Mol Biol 2009, 10:111.

37. Maloney KE, Valvano MA: The mgtC gene of Burkholderia cenocepacia is required for growth under magnesium limitation conditions and intracellular survival in macrophages. Infect Immun 2006, 74(10):5477-5486.

38. Hunt TA, Kooi C, Sokol PA, Valvano MA: Identification of Burkholderia cenocepacia genes required for bacterial survival in vivo. Infect Immun 2004, 72(7):4010-4022.

39. Malott RJ, Baldwin A, Mahenthiralingam E, Sokol PA: Characterization of the ccilR quorum-sensing system in Burkholderia cenocepacia. Infect Immun 2005, 73(8):4982-4992.

40. O'Grady EP, Viteri DF, Malott RJ, Sokol PA: Reciprocal regulation by the CepIR and CcilR quorum sensing systems in Burkholderia cenocepacia. BMC Genomics 2009, 10:441.

41. Sass A, Marchbank A, Tullis E, Lipuma JJ, Mahenthiralingam E: Spontaneous and evolutionary changes in the antibiotic resistance of Burkholderia cenocepacia observed by global gene expression analysis. BMC Genomics 2011, 12(1):373.

42. Naderer T, McConville MJ: The Leishmania-macrophage interaction: a metabolic perspective. Cell Microbiol 2008, 10(2):301-308.

43. Fukuto HS, Svetlanov A, Palmer LE, Karzai AW, Bliska JB: Global gene expression profiling of Yersinia pestis replicating inside macrophages reveals the roles of a putative stress-induced operon in regulating type III secretion and intracellular cell division. Infect Immun 2010, 78(9):3700-3715.

44. Sokol PA, Darling P, Woods DE, Mahenthiralingam E, Kooi C: Role of ornibactin biosynthesis in the virulence of Burkholderia cepacia: characterization of pvdA, the gene encoding L-ornithine $\mathrm{N}(5)$-oxygenase. Infect Immun 1999, 67(9):4443-4455 
45. Taylor CM, Osman D, Cavet JS: Differential expression from two ironresponsive promoters in Salmonella enterica serovar Typhimurium reveals the presence of iron in macrophage-phagosomes. Microb Pathog 2009, 46:114-118.

46. Van Zandt KE, Sow FB, Florence WC, Zwilling BS, Satoskar AR, Schlesinger LS, Lafuse WP: The iron export protein ferroportin 1 is differentially expressed in mouse macrophage populations and is present in the mycobacterial-containing phagosome. J Leukoc Biol 2008 , 84:689-700.

47. Wagner D, Maser J, Lai B, Cai Z, Barry CE, Höner zu Bentrup K, Russell DG, Bermudez LE: Elemental analysis of Mycobacterium avium-, Mycobacterium tuberculosis-, and Mycobacterium smegmatis -containing phagosomes indicates pathogen-induced microenvironments within the host cell's endosomal system. J Immunol 2005, 174:1491-1500.

48. Schmerk $C L$, Bernards MA, Valvano MA: Hopanoid production is required for low pH tolerance, antimicrobial resistance, and motility in Burkholderia cenocepacia. J Bacteriol 2011

49. Welander PV, Hunter RC, Zhang L, Sessions AL, Summons RE, Newman DK: Hopanoids play a role in membrane integrity and $\mathrm{pH}$ homeostasis in Rhodopseudomonas palustris TIE-1. J Bacteriol 2009, 191:6145-6156.

50. Burchmore RJ, Barrett MP: Life in vacuoles-nutrient acquisition by Leishmania amastigotes. Int J Parasitol 2001, 31(12):1311-1320.

51. Liu X, Matsumura P: The FlhD/FlhC complex, a transcriptional activator of the Escherichia coli flagellar class II operons. J Bacteriol 1994, 176(23):7345-7351

52. Porter SL, Wadhams GH, Armitage JP: Signal processing in complex chemotaxis pathways. Nat Rev Microbiol 2011, 9(3):153-165.

53. Szurmant H, Muff TJ, Ordal GW: Bacillus subtilis CheC and FliY are members of a novel class of CheY-P-hydrolyzing proteins in the chemotactic signal transduction cascade. J Biol Chem 2004, 279(21):21787-21792

54. Kanehisa M, Goto S: KEGG: kyoto encyclopedia of genes and genomes. Nucleic Acids Res 2000, 28(1):27-30.

55. Kanehisa M, Goto S, Furumichi M, Tanabe M, Hirakawa M: KEGG for representation and analysis of molecular networks involving diseases and drugs. Nucleic Acids Res 2010, 38(Database):D355-360.

56. Chuaygud T, Tungpradabkul S, Sirisinha S, Chua KL, Utaisincharoen P: A role of Burkholderia pseudomallei flagella as a virulent factor. Trans $R$ Soc Trop Med Hyg 2008, 102(Suppl 1):S140-144

57. Amiel E, Lovewell RR, OToole GA, Hogan DA, Berwin B: Pseudomonas aeruginosa evasion of phagocytosis is mediated by loss of swimming motility and is independent of flagellum expression. Infect Immun 2010, 78(7):2937-2945

58. Urban TA, Griffith A, Torok AM, Smolkin ME, Burns JL, Goldberg JB: Contribution of Burkholderia cenocepacia flagella to infectivity and inflammation. Infect Immun 2004, 72(9):5126-5134

59. Ortega XP, Cardona ST, Brown AR, Loutet SA, Flannagan RS, Campopiano DJ, Govan JR, Valvano MA: A putative gene cluster for aminoarabinose biosynthesis is essential for Burkholderia cenocepacia viability. J Bacteriol 2007, 189(9):3639-3644.

60. Roy $\mathrm{H}$ : Tuning the properties of the bacterial membrane with aminoacylated phosphatidylglycerol. IUBMB Life 2009, 61(10):940-953.

61. Nelson J, Gibbons E, Pickett KR, Streeter M, Warcup AO, Yeung CH, Judd AM, Bell JD: Relationship between membrane permeability and specificity of human secretory phospholipase $A(2)$ isoforms during cell death. Biochim Biophys Acta 2011, 1808(7):1913-1920.

62. Cheung KJ Jr, Li G, Urban TA, Goldberg JB, Griffith A, Lu F, Burns JL: Pilusmediated epithelial cell death in response to infection with Burkholderia cenocepacia. Microbes Infect 2007, 9(7):829-837.

63. Cunha LG Jr, Assis MC, Machado GB, Assef AP, Marques EA, Leao RS, Saliba AM, Plotkowski MC: Potential mechanisms underlying the acute lung dysfunction and bacterial extrapulmonary dissemination during Burkholderia cenocepacia respiratory infection. Respir Res 2010, 11:4.

64. McClean S, Callaghan M: Burkholderia cepacia complex: epithelial cellpathogen confrontations and potential for therapeutic intervention. Med Microbiol 2009, 58(Pt 1):1-12.

65. MacDonald $\mathrm{KL}$, Speert DP: Differential modulation of innate immune cell functions by the Burkholderia cepacia complex: Burkholderia cenocepacia but not Burkholderia multivorans disrupts maturation and induces necrosis in human dendritic cells. Cell Microbiol 2008, 10(10):2138-2149.
66. Cremer TJ, Shah P, Cormet-Boyaka E, Valvano MA, Butchar JP, Tridandapani S: Akt-Mediated Proinflammatory Response of Mononuclear Phagocytes Infected with Burkholderia cenocepacia Occurs by a Novel GSK3\{beta\}-Dependent, I\{kappa\}B Kinase-Independent Mechanism. J Immunol 2011.

67. Kotrange S, Kopp B, Akhter A, Abdelaziz D, Abu Khweek A, Caution K, Abdulrahman B, Wewers MD, McCoy K, Marsh C, et al: Burkholderia cenocepacia $\mathrm{O}$ polysaccharide chain contributes to caspase-1-dependent IL-1beta production in macrophages. J Leukoc Biol 2011, 89(3):481-488,

68. Figurski DH, Helinski DR: Replication of an origin-containing derivative of plasmid RK2 dependent on a plasmid function provided in trans. Proc Natl Acad Sci USA 1979, 76(4):1648-1652.

69. Sambrook J, Fritsch EF, Maniatis T: Molecular Cloning: a Laboratory Manual. Cold Spring Harbor, NY: Cold Spring Harbor Laboratory i 21990

70. Cohen SN, Chang AC, Hsu L: Nonchromosomal antibiotic resistance in bacteria: genetic transformation of Escherichia coli by R-factor DNA. Proc Natl Acad Sci USA 1972, 69(8):2110-2114.

71. Froussard $P: A$ random-PCR method ( $r P C R)$ to construct whole CDNA library from low amounts of RNA. Nucleic Acids Res 1992, 20(11):2900.

72. Daigle F, Hou JY, Clark-Curtiss JE: Microbial gene expression elucidated by selective capture of transcribed sequences (SCOTS). Methods Enzymol 2002, 358:108-122.

73. Rozen S, Skaletsky H: Primer3 on the WWW for general users and for biologist programmers. Methods Mol Biol 2000, 132:365-386.

74. Flannagan RS, Linn T, Valvano MA: A system for the construction of targeted unmarked gene deletions in the genus Burkholderia. Environ Microbiol 2008, 10(6):1652-1660.

75. Miller $V L$, Mekalanos JJ: A novel suicide vector and its use in construction of insertion mutations: osmoregulation of outer membrane proteins and virulence determinants in Vibrio cholerae requires toxR. J Bacteriol 1988, 170(6):2575-2583.

76. Cox GW, Mathieson BJ, Gandino L, Blasi E, Radzioch D, Varesio L: Heterogeneity of hematopoietic cells immortalized by v-myc/v-raf recombinant retrovirus infection of bone marrow or fetal liver. $J$ Natl Cancer Inst 1989, 81(19):1492-1496.

77. Aubert D, MacDonald DK, Valvano MA: BcsKC is an essential protein for the type VI secretion system activity in Burkholderia cenocepacia that forms an outer membrane complex with BcsLB. J Biol Chem 2010, 285(46):35988-35998.

78. Yanisch-Perron C, Vieira J, Messing J: Improved M13 phage cloning vectors and host strains: nucleotide sequences of the M13mp18 and pUC19 vectors. Gene 1985, 33(1):103-119

doi:10.1186/1471-2164-13-63

Cite this article as: Tolman and Valvano: Global changes in gene expression by the opportunistic pathogen Burkholderia cenocepacia in response to internalization by murine macrophages. BMC Genomics 2012 13:63.

\section{Submit your next manuscript to BioMed Central and take full advantage of:}

- Convenient online submission

- Thorough peer review

- No space constraints or color figure charges

- Immediate publication on acceptance

- Inclusion in PubMed, CAS, Scopus and Google Scholar

- Research which is freely available for redistribution 